\title{
RESEÑAS
}

\section{Milagros ALEZA IZQUIERDO (coordinadora): Normas y usos correctos en el español actual, Valencia, Tirant Humanidades, 2011 (edición corregida y actualizada), 500 páginas, ISBN 978-84-939316-0-5 ${ }^{1}$}

\author{
Reseñado por Juan Carlos TORDERA YLLESCAS \\ I. E. S. Ausiàs March (Manises)
}

Conocer la normativa lingüística no se restringe a ser capaz de construir un texto ortográficamente correcto, sino que conlleva la habilidad de construir puentes de interculturalidad entre el vasto dominio hispanohablante, ya que el objetivo de la norma no es otro que la inteligibilidad lingüística por encima de fronteras políticas, sociales e/o ideológicas. En esta etapa de desarrollo de los medios de comunicación y, especialmente, de expansión de las tecnologías digitales, la lengua española halla un amplio abanico de usuarios que conceptualizan el mundo en esta lengua, o que viven rodeados por un contexto hispanohablante, o que trabajan y negocian mediante esta lengua... Por tanto, el conocimiento de la norma lingüística nunca ha sido más necesario que en nuestro siglo presente. Por ello, la publicación de un libro, como el que no ocupa, es de suma importancia, ya que nos permite conocer una realidad tan altamente reclamada y aclamada como es el de la norma lingüistica y, sin embargo, a veces tan poco conocida.

Acercarse a un texto de normativa es una empresa que puede revelarse tediosa y poco atractiva. Sin embargo, hemos de señalar que la inusual claridad y la mesurada concisión con que se aborda el tema tratado facilitan su consulta de manera fácil y directa. La obra no deja de lado ningún nivel normativo; no solo nos acerca a las cuestiones más problemáticas de ortografía y morfosintaxis, sino que se abordan cuestiones tales como la lexicología, la lexicografía, la estilística (apartado complejo resuelto con cuidadosa sencillez), la ortología (apartado relevante que no siempre es tenido en cuenta), la ortotipografía (apartado necesario para la labor editora)... Por tanto, hemos de señalar que esta obra, fundamentada en el Diccionario panhispánico de dudas, la Nueva gramática de la lengua española y, en su segunda edición, en la recientemente publicada Ortografía de la lengua española, consigue ordenar, sintetizar y aclarar las cuestiones más controvertidas de la normativa.

\footnotetext{
${ }^{1}$ La primera edición fue publicada en la editorial Tirant lo Blanch, 2010 (ISBN: 978-84-9876-869-5)-
} 
Aproximándonos a los contenidos tratados, hemos de señalar que el presente volumen, redactado por profesores e investigadores de la Universitat de València, de la Universidad Católica de Valencia («San Vicente Mártir») y de la Universidad de Granada, aborda aspectos de la lengua española candentes en la actualidad, prestando especial atención al desarrollo del español (oral y escrito) en los medios de comunicación. Como se ha indicado, para analizar estos usos se incluye información de las tres obras académicas. Por otra parte, hay que destacar que muchos de los capítulos se apoyan en el resultado de investigaciones recientes.

La facilidad y claridad de las explicaciones teóricas se ven complementadas con la presentación de ejercicios que persiguen comprobar la adecuada comprensión de los contenidos más controvertidos y esquivos de retener. Por todo ello, el didactismo de esta obra se fundamenta en el hecho de que la exhaustividad y claridad teórica se ven reforzadas por la introducción de una ponderada selección de ejercicios.

La obra, coordinada por Milagros Aleza, se abre con dos capítulos, escritos respectivamente por Amparo Ricós y Milagros Aleza, en los que se exponen cuestiones relacionadas con el origen e historia de la lengua española y su situación actual, es decir, el español como lengua de proyección internacional (capítulo 1), con especial atención a la existencia de las variantes diatópicas, diastráticas y diafásicas (capítulo 2); es decir, de manera somera, se realiza una aproximación a la lengua española como un diasistema, esto es, un sistema de sistemas, por lo que se da cuenta de la realidad proteica y heterogénea de la lengua.

En los capítulos 3, 4 y 5, se ofrece una descripción de las cuestiones normativas de gramática (elaborado por Milagros Aleza), ortografía (a cargo de Adela García) y ortología (redactado por Marta Albelda). Así, en el capítulo 3 se abordan los usos e irregularidades frecuentes en el español actual, las estructuras problemáticas que se manifiestan en todos los niveles socioculturales, y de las que no se escapa ni siquiera la lengua escrita. Se complementa con una segunda parte escrita por Eduardo España, en la que se proponen diversos ejercicios gramaticales que tratan de consolidar los conocimientos adquiridos. En el capítulo 4, dada la importancia de la acentuación y los signos de puntuación para la redacción correcta de textos, se tratan ambas cuestiones con sumo detalle y con la adjunción final de ejercicios. Es de especial interés el apartado de ortografía por su cuidada atención a la puntuación y, especialmente, al uso de la coma, ya que la puntuación no es más que el reflejo escrito de la sintaxis normativa. En el capítulo 5 se presentan los aspectos básicos de la ortología del español, atendiendo a una perspectiva normativa, descriptiva y prescriptiva, centrándose en la correcta y adecuada pronunciación de los sonidos. El capítulo finaliza con una serie de ejercicios.

Los capítulos 6, 7, 8, 9 y 10 abordan cuestiones lexicológicas relevantes. El capítulo 6, de María Estornell, se ocupa de la creación léxica motivada por las novedades que surgen en la realidad, así como por otros fines discursivos. Se presentan ejercicios con el fin de aplicar los conocimientos adquiridos sobre el tema.

El capítulo 7, de David Giménez, trata, de forma muy práctica, la actualidad de los extranjerismos en el Diccionario panhispánico de dudas, los procesos de adaptación 
y los criterios que se han utilizado en la obra académica para tal fin, por lo que incluye ejercicios y ofrece estrategias o trucos para utilizar correctamente los extranjerismos.

Por su parte, el capítulo 8, de Julia Sanmartín, se encarga de la elección léxica que se lleva a cabo al redactar los distintos géneros discursivos, partiendo de la consideración de que los géneros se encuentran asociados a ámbitos comunicativos determinados. También se incluyen ejercicios.

El capítulo 9, a cargo de Esteban Montoro, trata sobre el fenómeno de las colocaciones, esto es, combinaciones de dos o más palabras que muestran cierta tendencia a coaparecer en el habla y, en ocasiones, mantienen una relación de implicación semántica. Además, presenta ejercicios prácticos de ejercitación.

El último capítulo de este bloque, capítulo 10, elaborado por Marta Pilar Montañez, se encarga (a través de ejercicios) de diversos fenómenos relacionados con la precisión y la ampliación léxicas: la relación de significados (sinonimia, antonimia), la confusión de significados (homonimia, parónimos, impropiedades y errores léxicos), la disponibilidad de vocabulario (hiperonimia e hiponimia, sustitución de proformas léxicas), y otras cuestiones estilísticas.

En el capítulo 11, de Virginia González, se repasan las diferentes obras estimadas indispensables para cualquier estudiante, profesor o profesional que maneje la lengua española. Igualmente, se registran las diversas herramientas disponibles para resolver dudas y mejorar las producciones escritas y orales (v. gr.: diccionario de dudas, gramáticas, manuales de normativa...).

En el capítulo 12, a cargo de Marta Albelda, se estudian la atenuación, los eufemismos y el lenguaje políticamente correcto, es decir, se tratan las tres herramientas básicas de la manipulación lingüística del significado. Se ofrece una propuesta de caracterización y se señalan las consecuencias que provocan en la comprensión de los mensajes. Como en muchos de los capítulos, se incluyen también ejercicios. En el capítulo 13, escrito por Mercedes Quilis, desde una perspectiva lingüística y normativa, se tratan cuestiones relacionadas con el género gramatical y el sexismo lingüístico. En concreto, se registran las últimas propuestas léxicas para la creación de nuevos femeninos de los nombres personales referidos a profesiones. (p. e., ¿se puede decir la juez o es la jueza? ¿la médico o la médica?).

Los dos últimos capítulos están destinados a la composición de textos. En el capítulo 14, redactado por Antonio Hidalgo, dirigido a la corrección de estilo, se describen los requisitos principales (textuales, gramaticales, léxico...) que se han de tener en cuenta en el proceso de redacción de un texto. Finalmente, el objetivo del capítulo 15, escrito por María Estellés y Adrián Cabedo, es la descripción de trabajos de investigación. Este capítulo supone una guía muy práctica para crear textos correctos y adecuados en el ámbito universitario, tanto formal como conceptualmente.

En definitiva, estamos ante una obra muy completa y cuidadosamente elaborada, que, sin duda, contribuirá a un mejor conocimiento de la lengua española actual. 
